\title{
Modelling the loss of time caused by traffic incidents on motorways
}

\author{
Krystian Birr ${ }^{1,}$, and Barbara Strzebrakowska ${ }^{1}$ \\ ${ }^{1}$ Gdansk University of Technology, Faculty of Civil and Environmental Engineering, Department of \\ Highway and Transportation Engineering, 11/12 Narutowicza str., 80-180, Gdansk, Poland
}

\begin{abstract}
For each road incident important factors like location, capacity reduction, traffic management, duration of road incidents and amount of traffic should be defined. All performer operations and effects of incidents affect the capacity of the road, average speed, time loss, vehicle queues and traffic jams. In the article road incidents were divided into planned and unexpected. Statistical analysis prepared using the database of traffic events which occurred on highways and expressways in Pomeranian Voivodeship is presented considering location of incidents on each road, frequency and duration of incidents and duration of rescue operation. Furthermore, the cases used to calibrate the model are characterised. Subsequently, the method of estimation of time loss resulting from incidents is presented. Within the methodology, mathematical and simulation models are distinguished. The tools for dynamic traffic modelling are also presented. In the last part of the article, the method of calculation value of time loss is presented.
\end{abstract}

\section{Introduction}

Every day road users choose their means of transport, the route and consequently travel time so that their journey is the most efficient in terms of duration, convenience and expense. In the case of regular journeys road users, over time, decide on the best route variant, which results in the traffic reaching equilibrium, meaning that no other decision would result in a lower cost for their journey [1]. The network in a condition of equilibrium as a typical state, that contrary to appearances, is very rare. Changes in traffic conditions occur often, caused by planned events such as holidays or mass events. In the case of unexpected events (accident, collision, breakdown, etc.), it is important to provide drivers with information using modern solutions (smartphone applications, navigation, internet services, variable message signs and others) [2]. Based on the received information, road users can decide to change their travel route or even opt out of travel.

Traffic incidents occur relatively often, and their effects are very different, depending on the incident type and features. Victims and material losses constitute the effects of such incidents. However, an incident is not always related to this kind of loss, because it is any phenomenon that causes disturbances in the balanced distribution of traffic on the network,

\footnotetext{
${ }^{*}$ Corresponding author: krystian.birr@pg.edu.pl
} 
which affect the time loss for road network users. A traffic incident means not only accidents, collisions or breakdowns, but also related works as well as various planned events.

\section{Problem identification}

\subsection{Impact of road traffic incidents on traffic conditions}

Road accidents may result in the obstruction of normal passage through a section, interchange or junction, which involves a change in traffic conditions resulting from the changed parameters of the network. The values of these parameters can alter over time. The effects of each incident affect the interdependent parameters of the traffic and transport network [3], such as the capacity of the section or intersection and the average speed of travel.

The decrease in capacity caused by a traffic incident depends on the road section (the total number of lanes in each direction) and the number of blocked lanes. The study carried out in 2002 [4] showed that, for example, a block on one lane on a two-lane expressway reduced the road capacity by about $68 \%$ in the direction where the road accident occurred. Table 1 presents detailed results for different situations, differentiated in terms of road cross-section and the number of blocked lanes.

Table 1. Percentage capacity of the section during the road incident [4].

\begin{tabular}{|l|c|c|c|c|c|}
\hline \multirow{2}{*}{ Type of restriction } & \multicolumn{5}{|c|}{ Capacity during incident (\%) } \\
\cline { 2 - 6 } & \multicolumn{5}{|c|}{ Lane number - Express Road } \\
\cline { 2 - 6 } & 1 lane & 2 lanes & 3 lanes & 4 lanes & 5 lanes \\
\hline Vehicles in emergency lane & 0,45 & 0,75 & 0,84 & 0,89 & 0,93 \\
\hline 1 blocked lane & 0,00 & 0,32 & 0,53 & 0,56 & 0,75 \\
\hline 2 blocked lanes & - & 0,00 & 0,22 & 0,34 & 0,50 \\
\hline
\end{tabular}

From the point of view of road traffic analysis, the main effect of the reduced road section capacity is the time loss for road users who are indirectly affected by the effect of a road incident in the form of extended driving time [5]. The loss of time should be understood as the difference between the average total travel time in standard traffic conditions (without a traffic incident) and the total travel time if an event occurs at the same time and area.

\subsection{Driver time loss modelling methods}

Based on studied literature, the authors found many methods for estimating the time loss for road users in the occurrence of a road incident on the road network. This article focuses on analyses of the road network area, including alternative routes to the road on which traffic incidents occur. Time loss can be estimated for each case, referring to the parameters of the road network, current traffic, the duration and type of event [5]. Mathematical models, using queueing theories as well as more complicated computational ones included in macroscopic, mesoscopic and microscopic traffic simulation models, can be used for calculations. Each of these methods can be used to analyse the time loss for road users caused by road incidents [6]. The use of simulation models for a large area of the transport network containing alternative roads allows to account for the time loss for all network users, including those on routes where the analysed traffic incident did not occur, but the traffic volume increased due to the route change of other users, in particular those directly affected by the event. 


\section{Method for estimating time loss}

\subsection{Assumptions for analysis}

Seven traffic incidents were selected for the analysis, which included road lane closure or significant damage to the infrastructure and the associated closure of the emergency lane. The analysed traffic incidents are presented in Table 1.

Table 1. Data on traffic incidents on the A1 motorway from July 2017.

\begin{tabular}{|c|c|c|c|c|c|c|c|}
\hline 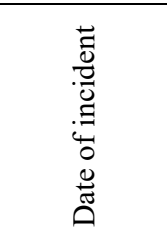 & 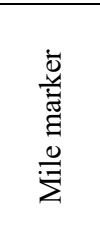 & 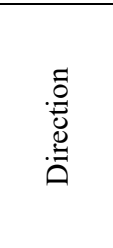 & 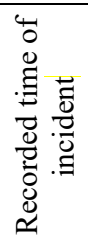 & 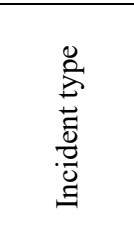 & 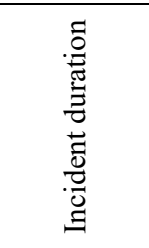 & 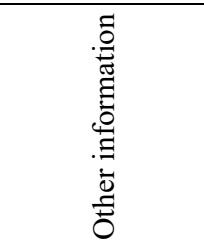 & 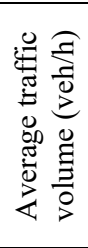 \\
\hline 03.07 .2017 & 22,95 & Toruń & $13: 50$ & Other & No data & $\begin{array}{c}\text { Theft, } \\
\text { perpetrator } \\
\text { unknown }\end{array}$ & 1900 \\
\hline 09.07 .2017 & 18,45 & Toruń & $17: 50$ & Collision & $45 \mathrm{~min}$ & $\begin{array}{c}\text { Securing the } \\
\text { emergency } \\
\text { lane from } \\
18: 12 \text { to } 18: 35\end{array}$ & 1600 \\
\hline 10.07 .2017 & 22,20 & Toruń & 19:00 & Collision & $2 \mathrm{~h} 10 \mathrm{~min}$ & $\begin{array}{l}\text { Securing the } \\
\text { collision in the } \\
\text { emergency } \\
\text { lane from } \\
\text { 19:00 to } 22: 10\end{array}$ & 1500 \\
\hline 15.07 .2017 & 17,10 & Gdańsk & $10: 50$ & Collision & No data & No perpetrator & 1800 \\
\hline 22.07 .2017 & 17,51 & Gdańsk & $4: 50$ & Accident & 1h $38 \mathrm{~min}$ & $\begin{array}{l}\text { Closure of } \\
\text { right lane and } \\
\text { emergency } \\
\text { lane from } 5: 11 \\
\text { to } 6: 28\end{array}$ & 800 \\
\hline 26.07 .2017 & 20,73 & Toruń & $11: 33$ & Accident & $5 \mathrm{~h} 12 \mathrm{~min}$ & $\begin{array}{c}\text { Closure of left } \\
\text { lane in } \\
\text { kilometre } \\
20+500- \\
20+810 \text { from } \\
11: 33 \text { to } 16: 45\end{array}$ & 1800 \\
\hline
\end{tabular}

In order to develop a simulation model for the calculation of time loss resulting from the above incidents, the area of the road network in the vicinity of these incidents was determined, with particular reference to alternative routes that may have been selected by some drivers due to disruptions in traffic. The area where the simulation was conducted covered a total of $1342 \mathrm{~km}$ of roads, including $36 \mathrm{~km}$ of the A1 motorway from Rusocin to the Pelplin interchange (Figure 1). 


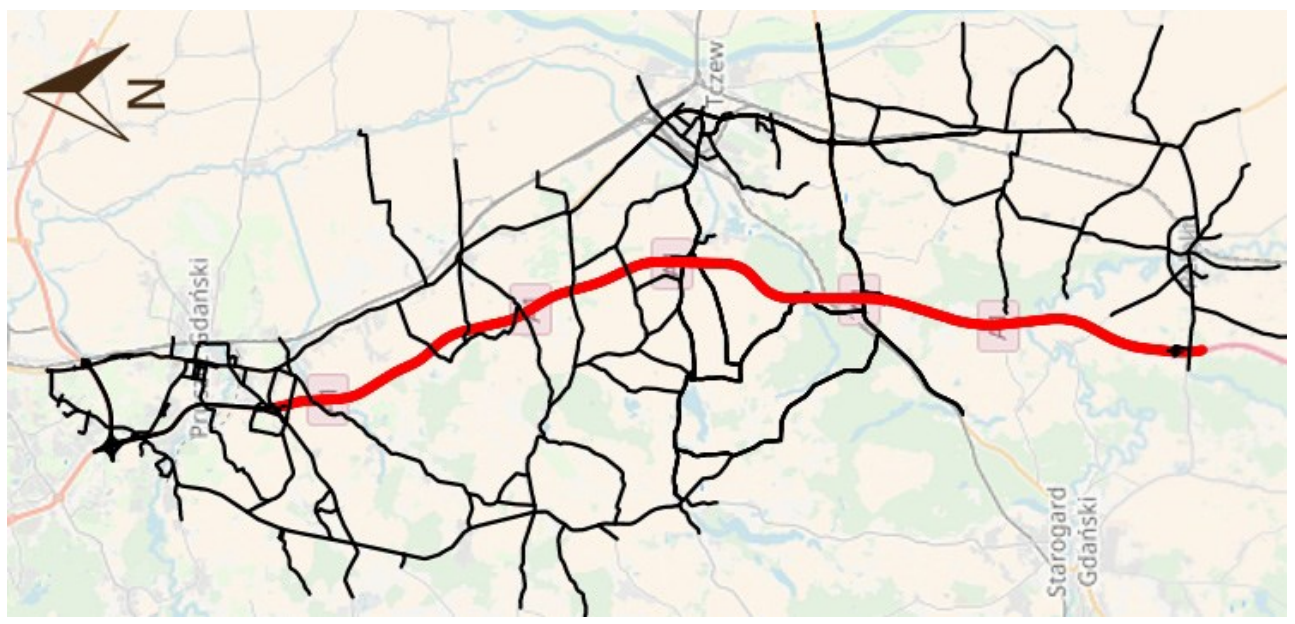

Fig. 1. Area of simulation studies (source of the base map: openstreetmap.com authors).

\subsection{Input data}

Data on incidents that took place in July 2017 were obtained to calibrate the simulation model. This month was chosen due to heavy traffic and numerous traffic incidents. In order to simulate the effect of a road incident, it is necessary to provide information on traffic volume at the time of the incident, its duration, location, how quickly the queue of vehicles accumulated, how long the queue was and how long it took to restore normal traffic flow. Traffic volume data on the motorway were obtained from GTC S.A., which currently manages the A1 motorway on the section Gdańsk - Torun. The data contain traffic volume on all motorway exits in a 1-hour time interval. Data on traffic incidents, that came from GDDKiA Gdańsk database, were supported by detailed information from GTC.

Data on the impact of traffic incidents were obtained from CE Traffic who deal with realtime traffic monitoring, among others, in Poland. The data include typical vehicle speeds on the motorway section from the Rusocin interchange to the Pelplin interchange, which is the Tczew city area, the average speed of vehicles on alternative routes to the A1 motorway and the average speed of vehicles on the network at the time of road incidents. Data were mapped for sections of approx. $100 \mathrm{~m}$ in length. Time intervals for average speeds were 1 hour, and in the case of periods of road event occurrence - 5 minutes for the A1 motorway and 15 minutes for alternative roads. The results were mapped with the division into light and heavy vehicles.

Average vehicle speed was determined based on data from vehicles that were equipped with GPS devices or data from applications and personal navigation devices. Among others, the instantaneous speed of the vehicle was recorded at a given point on the road. If it was available, the information on the type of vehicle was obtained (fleet vehicles), in other cases the vehicle type was determined by its behaviour.

Result data were compiled on the so-called 3D charts, i.e. mapping a kilometre of the road, time and speed of vehicles (Fig. 2). The individual speed ranges are marked with colours, which make it possible to indicate quickly the traffic incident. Figure 2 presents an example of a speed graph for the A1 motorway in the direction of Torun. Distance is marked on the horizontal axis, on the vertical axis - time, while in individual positions the values of average vehicle speeds on $100 \mathrm{~m}$ sections are given in accordance with the colours included in the legend. 


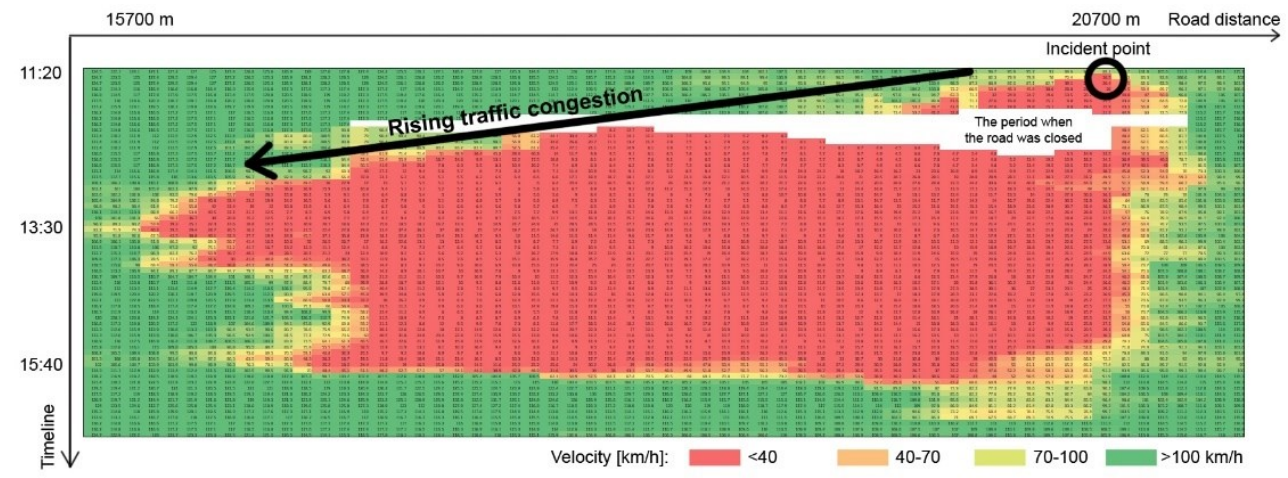

Fig. 2. Diagram for distance, time and speed dependency for the traffic incident of July 26, 2017.

\subsection{Simulation tools}

To simulate a traffic incident, an advanced simulation tool was chosen which is a travel model with dynamic network traffic distribution, encoded in the PTV VISUM program with the TRE module (Traffic Realtime Equilibrium). TRE is a software for the computation of dynamic assignment where path choices and demand loading depend on the travel times obtained through any network simulation model which assumes the resulting node splitting rates. Two types of calculation procedures of the TRE module were applied in the study [2]: - Dynamic Traffic Assignment - full dynamic assignment method with route-choice and equilibrium, to simulate design scenarios on large highways or urban signalised networks. User path choice behaviour can be deterministic or stochastic (Logit). Multimodality is fully supported;

- Events and Rerouting - conceived for incident management planning and evaluation. It provides traffic pattern for the cases of unexpected traffic events, providing invaluable decision and operational design support for incident management.

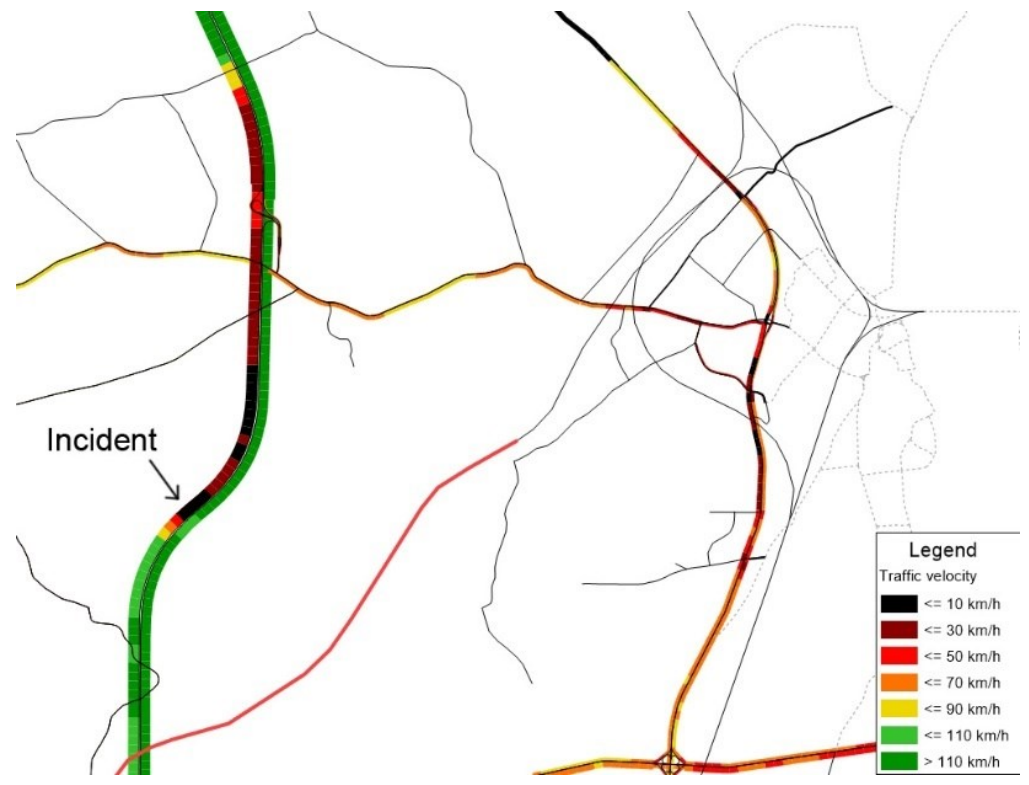

Fig. 3. Cartogram of the result of the traffic conditions simulation - vehicle speeds for a traffic incident of 26/07/2017, 13.30 . 


\subsection{Study results}

Vehicle time losses were calculated by comparing the veh/hour values on the analysed road network for the following states: with a traffic incident and without a traffic incident. The demonstrated difference was defined as the time loss due to this event.

For events that resulted in the closure of an emergency lane, a slight reduction in average speed of travel was observed (up to $10 \mathrm{~km} / \mathrm{h}$ ), which is associated with relatively small losses of vehicle time. In the case of other types of traffic restrictions, i.e. closure of traffic on one lane or the entire road section, these losses are much higher.

The analyses performed showed that the time loss depends mainly on the duration of the event $t$ (traffic restrictions) and the traffic volume of vehicles $Q$ in relation to the capacity of the road in the state of traffic restriction. These dependencies are linear. The analyses accounted for changes in the route, resulting from received information about the occurring event by drivers approaching the area of a road incident impact.

Based on the calibrated traffic model, exemplary simulations of the traffic distribution for differentiated states with the occurring traffic incident were conducted. Individual states were differentiated in terms of average traffic volume per hour $Q$, duration of event $t$ and its type. Table 2 and figure 3 show examples of results for an event which caused a closure of one lane.

The lowest losses of time were recorded for the traffic volume $Q=1000 \mathrm{veh} / \mathrm{h}$ which results, among others, from the fact that the capacity of one lane (cleared) is much greater, which means that any potential congestion is cleared in a short time. The opposite situation occurs for scenarios assuming traffic volume of $\mathrm{Q}=2,500 \mathrm{veh} / \mathrm{h}$ in which the queue of vehicles is cleared only when the route of some drivers changes.

Table 2. Time loss due to a blocked lane after a traffic incident.

\begin{tabular}{|c|c|c|c|}
\hline \multirow{2}{*}{ Average traffic volume Q [veh/h] } & \multicolumn{3}{|c|}{ Incident duration t (hours) } \\
\cline { 2 - 4 } & $\mathbf{1}$ & $\mathbf{3}$ & $\mathbf{5}$ \\
\hline 1000 & 124.9 & 240.2 & 393.1 \\
\hline 1800 & 411.1 & 1499.9 & 2426.0 \\
\hline 2500 & 1350.5 & 3996.2 & 6932.5 \\
\hline
\end{tabular}

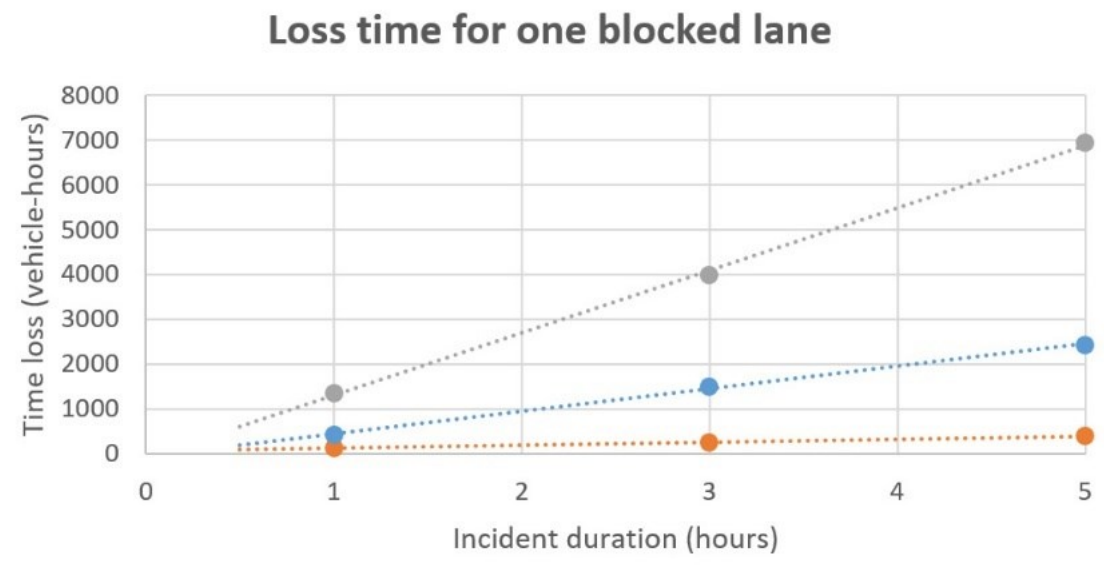

- $\mathrm{Q}=1000 \mathrm{Q}=1800$ - $\mathrm{Q}=2500$

Fig. 3. Time loss resulting from one lane blocked a traffic incident. 


\section{Conculsions}

\subsection{Summary}

The use of the advanced simulation tool, which is a dynamic traffic model for simulating road events, allows for calculation of potential traffic incidents and their consequences. To calibrate the model, it is necessary to collect possibly accurate data describing vehicle movement parameters and road network load in the period before, after and during the traffic incident. The data sources on vehicle speed presented in the article, originating from various devices determining vehicle positions (mobile phones, car navigation, etc.), as well as data on traffic volume from automatic counters, transport management, etc., enable the calibration of a dynamic traffic model and simulation of other road events. It is important, however, that this model be extended to simulate drivers' decisions regarding changes to the previously selected route. These changes can be made on using information received about a traffic incident transmitted by radio, navigation, mobile applications, as well as drivers' direct observation.

The simulation studies presented in this article showed that the time losses for vehicles caused by a road incident increase linearly with respect to the duration of this event. The rate of increase in time loss depends directly on the volume of traffic.

The conducted simulations and analyses are the starting material for the development of a mathematical model that allows for estimating the loss of time for drivers caused by various types of road accidents on motorways. The construction of the model is directly the next step of the study carried out as part of the project Development of Road Innovation - 3B: "The impact of time and operating conditions on the durability and functionality of road safety components". The results obtained using this model enable the cost estimation of road barriers life cost.

\section{References}

1. R. Kucharski, G. Gentile, Modelowanie zjawiska zmiany trasy przejazdu w dynamicznym rozkładzie ruchu w sieci drogowej, in: Res. Tech. J. Polish Assoc. Transp. Eng. Cracow, (Cracow, Poland, 2014)

2. R. Kucharski, Modelowanie zjawisk zmiany trasy przejazdu w sytuacjach nietypowych, Cracow University of Technology, 2015

3. PB Farradyne, Traffic Incident Management Handbook (Federal Highway Administration, 2000)

4. E. Chin, O. Franzese, D.L. Greene, H. Hwang, R. Gibson, Temporary losses of highway capacity and impacts on performance (National Transportation Research Centre, 2002)

5. S. Gaca, W. Suchorzewski, M. Tracz, Road traffic engineering. Theory and practice (in Polish) (WKŁ, Warsaw, 2008)

6. B. Strzebrakowska, Simulation of the impact of dangerous road incidents on driver's loss of time on express roads, MATEC Web Conf. 122 (2017). doi:https://doi.org/10.1051/matecconf/201712202004 